\title{
Resveratrol post-treatment protects against neonatal brain injury after hypoxia-ischemia
}

\author{
Shulin Pan ${ }^{1, *}$, Songlin $\mathrm{Li}^{2,}{ }^{*}$, Yingying Hu${ }^{1}$, Hao Zhang ${ }^{1}$, Yanlong Liu ${ }^{3}$, Huai Jiang ${ }^{1}$, \\ Mingchu Fang ${ }^{1}$, Zhengmao $\mathrm{Li}^{3}$, Kebin $\mathrm{Xu}^{3}$, Hongyu Zhang ${ }^{3}$, Zhenlang Lin ${ }^{1}$, \\ Jian Xiao ${ }^{3}$ \\ ${ }^{1}$ Department of Neonatology, The Second Affiliated Hospital and Yuying Children's Hospital, Wenzhou Medical University, \\ Wenzhou 325000, China \\ ${ }^{2}$ The Institute of Life Sciences, Wenzhou University, Wenzhou 325035, China \\ ${ }^{3}$ The School of Pharmacy, Wenzhou Medical University, Wenzhou 325035, China \\ *These authors contribute equally to this work
}

Correspondence to: Jian Xiao, email: xfxj2000@126.com

Zhenlang Lin, email: linzhenlang@hotmail.com

Keywords: resveratrol, hypoxia-ischemia, brain damage, inflammation, apoptosis

Received: July 25, 2016 Accepted: October 19, $2016 \quad$ Published: November 02, 2016

\section{ABSTRACT}

Neonatal hypoxic-ischemic brain injury is a devastating disease with limited treatment options. Preventive treatment with resveratrol has indicated to be well tolerated and has lower toxicity in both experimental models and human patients. However, whether resveratrol administration post-hypoxic-ischemic protects against neonatal hypoxic-ischemic injury is not known. Here we reported that post-treatment with resveratrol significantly reduced brain damage at 7-day after the injury. We found that resveratrol reduced the expression levels of key inflammatory factors at the mRNA and protein levels, and at least partially via inhibiting microglia activation. Moreover, resveratrol exerted an anti-apoptotic effect, as assessed by TUNEL staining, and altered the expression of the apoptosis-related genes Bax, Bcl-2 and caspase3. Our data indicate that post-treatment with resveratrol protects against neonatal hypoxicischemic brain injury and suggest a promising therapeutic strategy to this disease.

\section{INTRODUCTION}

Neonatal encephalopathy due to perinatal hypoxiaischemia (HI) is a devastating disease that is a main cause of mortality in infants. The disease can lead to long-term neurological deficits, such as cerebral palsy, epilepsy, learning impairment and mental retardation. Currently, the therapeutic strategies for attenuating the injury in the clinical setting are limited. Hypothermia is now established as the standard treatment, but that modality is only partially effective and has a narrow therapeutic window of 6 hours [1]. Thus, finding new treatments to provide safe and efficient protection to neonates suffering from $\mathrm{HI}$ is critical.

Inflammation plays a critical role in mediating brain injury induced by neonatal hypoxic-ischemic brain injury. Hypoxia-ischemia triggers inflammation minutes after the insult [2], and increasing evidence shown that post-HI is responsible for the exacerbation of the brain damage.
The key components of inflammation include immune cells, adhesion molecules, cytokines, chemokines and oxidative stress [3]. Another event, apoptosis, frequently occurs in pathophysiological settings of nervous system injury and disease, notably following neonatal HI [4]. Apoptosis is an important mechanism of cell death after $\mathrm{HI}$ in the immature brain [5] that accounts for the delayed cell death that contributes to a significant proportion of the final cell loss after HI $[1,3,6]$. Components of the apoptotic pathways are several times more pronounced in immature than in juvenile and adult brains [7]. Other mechanisms of HI-induced brain damage include oxidative stress, excitotoxicity and the activation of other cell death pathways. Because the exacerbation of the brain injury comes from various pathological processes, therapeutic strategies that can target multiple mechanisms could be useful in limiting post-HI in neonatal brain damage.

Resveratrol (3,4',5- trihydroxystilbene; RSV), a naturally occurring polyphenolic compound, has broad 
physiological and pharmacological properties, including anti-aging, anti-carcinogenic, anti-inflammatory, antioxidant and anti-apoptotic properties [8-10]. Studies have identified a neuroprotective role for resveratrol in animal models of central nervous system diseases such as Alzheimer's disease, and cerebral ischemia/reperfusion injury [9, 11-15]. The experimental studies in vivo shown that resveratrol is well tolerated and has low toxicity $[16,17]$. Thus the rapid adoption of resveratrol has been tested in clinical trials, including for overweight/obesity, diabetic/metabolic syndrome, cancer and cardiovascular disease [18-21]. In addition, several studies have investigated its effect on the central nervous system in human adults [22, 23]. And no adverse effects of resveratrol were reported in the majority of human studies [24]. The characteristics of being well-tolerated and low toxicity are important criteria for the application of a drug in medicine, particularly in neonates. Pretreatment with resveratrol has been reported to attenuate perinatal hypoxic-ischemic brain injury [24-26]. However, few studies have reported whether post-treatment with resveratrol can protect against neonatal hypoxic-ischemic brain injury.

In this study, we found that post-treatment with resveratrol has a neuroprotective effect on neonatal hypoxicischemic brain injury and that the effect is related to the inhibition of inflammation and apoptosis. The post-insult administration regimen of resveratrol has greater clinical relevance than pre-insult administration does, and its various mechanisms of action described may provide useful insights into limiting post-HI in neonatal brain damage.

\section{RESULTS}

\section{$\mathrm{RSV}$ reduces brain tissue loss after $\mathrm{HI}$ injury in the neonatal rats}

To gain general information of the hypoxicischemic brains, the H\&E staining and the MBP/MAP2 immunohistochemical reactivity were performed using tissues collected at $7 \mathrm{~d}$ post-injury. Brains from the sham group appeared normal; both cerebral hemispheres had a similar appearance (Figure 1A). The hemispheres ipsilateral to the ligated side from the HI group exhibited atrophy and liquefaction with an obvious collapse (Figure 1B), but the brain atrophy was alleviated in the RSV group (Figure 1C). We further compared histopathological and neuronal alterations in the cortex and hippocampal dentate gyrus after the HI injury via HE staining and Nissl staining.

There was a remarkable tissue loss in the hippocampus and cortex after $\mathrm{HI}$ injury (Figure 1E, 1H and Figure 2B, 2E). However, this damaged brain tissue was significantly decreased in the RSV group compared to the HI group (Figure 1F, 1I and Figure 2C, 2F). Morphologically neurons with round and pale stained nuclei were normally seen throughout the cortex and hippocampus in the sham group (Figure 1D, 1G and Figure 2A, 2D). In the HI group, there was a marked increase in the number of dying cells, characterized by shrunken cells with pyknotic nuclei and even the absence of neurons (Figure $1 \mathrm{H}$ and Figure 2E). Post-treatment with resveratrol decreased the number of dying cells as well as the area of tissue damage (Figure 1I and Figure 2F).

In addition, there was a significant difference in neuronal (MAP2 - positive area) and oligodendrocyte (MBP - positive area) loss between RSV-treated rats and vehicle at 7 days after HI. A significant reduction in the MAP2-positive and MBP-positive area losses was also observed in the RSV group versus the HI group (Figure 3A, 3B).

\section{Anti-inflammatory effects of RSV}

To test the effect of inflammation after hypoxicischemic brain injury, several inflammatory markers were measured $24 \mathrm{~h}$ after HI injury, at which inflammatory response can be reliably detected but irreversible brain damage has not yet occurred. Real-time RT-PCR was used to evaluate the effect of post-treatment with resveratrol after hypoxia-ischemia on the mRNA expression levels of various inflammatory mediators. Four cytokines (TNF- $\alpha$, IL-18, IL-1 $\beta$ and IL-6) and another inflammatory factor COX-2 were significantly up-regulated in the hippocampus (Figure 4A) and cortex (Figure 4B) in the HI group. However, the inflammatory factors significantly decreased in the RSV group (Figure 4A, 4B).

Immunofluorescence of IL- 6 and TNF- $\alpha$ showed a slight expression in both hippocampus and cortex in the sham group (Figure 5A, 5B and Figure 6A, 6C). Immunohistochemically, strong positive immunoreactivity for IL- 6 and TNF- $\alpha$ were found in the HI group, suggesting a dramatic release of inflammatory cytokines in the hippocampus (Figure 5A and Figure 6A) and cortex (Figure $5 \mathrm{~B}$ and Figure $6 \mathrm{C}$ ). In the RSV group, we observed reduced fluorescence signal for IL- 6 and TNF- $\alpha$, respectively. The TNF- $\alpha$ western blot analysis results corresponded with the immunofluorescence of the same marker. The levels of TNF- $\alpha$ in the hippocampus was expressed at the lowest level in the sham group, and dramatically increased after HI (Figure 6B). The protein expression of TNF- $\alpha$ in the RSV group was significantly suppressed $(P<0.05)$ compared to the HI group (Figure 6B).

Microglia are the resident inflammatory cells in the central nervous system and a prominent source of inflammatory cytokines after brain injury. We then examined the effect of RSV on microglial activation by assessing immunohistochemical staining of Iba1, a marker of microglia. The microglial numbers were enormously elevated in the hippocampal dentate gyrus and cortex after HI (Figure 7B, 7E and 7A, 7D). In contrast, the number of microglia was markedly reduced in the RSV group (Figure 7C, 7F) 


\section{Anti-apoptotic effect of RSV}

TUNEL staining provided us with knowledge about the neuronal damage based on DNA breaks. In the hippocampus (Figure 8A) and cortex (Figure 8B) at $24 \mathrm{~h}$ after HI brain injury, the number of TUNEL-positive cells increased significantly in the HI group compared to the sham group. However, this increase in the number of apoptotic cells was significantly attenuated in the RSV group in comparing to the HI group (data not shown). We further assessed expression levels of several apoptosisrelated genes Bax, Bcl-2 and cleaved caspase 3. Western blot, immunochemistry and immunofluorescence for the pro-apoptotic factor Bax and anti-apoptotic factor Bcl-2 revealed a consistent effect of resveratrol intervention with our data above. Resveratrol intervention obviously inhibited the HI-induced up-regulation of Bax in the hippocampus and cortex (Figure 9A-9D). The Bcl-2 levels in the brain were low in the HI group (Figure 10), whereas post-treatment with resveratrol increased significantly Bcl-2 expression after HI (Figure 10) compared with the HI group. This effect of resveratrol corresponded to its antiapoptotic role, which was demonstrated by the reduction of TUNEL-positive cells and level of Bax (Figure 8).

Cleaved caspase 3 , which is the terminal executing enzyme for cleavage of substrate, was measured $24 \mathrm{~h}$ after $\mathrm{HI}$ to examine the effects of $\mathrm{HI}$ and RSV on neuronal apoptosis. Immunofluorescent staining in the hippocampus (Figure 11A) and cortex (Figure 11B) revealed more caspase 3 signals in the HI group when compared to the sham. However, cleaved caspase 3-positive cells were reduced in the RSV group versus the HI group. These results indicated that the neural protective effect of resveratrol might be at least partially through modulating the expression of apoptosis-related proteins.

\section{DISCUSSION}

Neonatal hypoxic-ischemic brain injury is an important neurological disorder associated with neonatal death and long-term disability. Its mechanisms include apoptosis, excitoxicity, inflammation and oxidative stress [3]. As the standard of clinical treatment, however, hypothermia has limited utility [27]. Here we found that post-treatment with resveratrol significantly reduced brain damage, decreased the protein levels of key inflammatory factors, and altered the expression of the apoptosis-related genes after the HI injury. Our data suggest a promising therapeutic strategy to the neonatal hypoxic-ischemic brain injury.

Resveratrol has been shown to have a number of physiological properties, such as anti-oxidant, antiinflammatory, anti-aging and anti-viral activities. Further, the preventive administration of resveratrol has been demonstrated to play neuroprotective role in the CNS experimental models, including Alzheimer disease, Parkinson's-like disease, Huntington's disease, subarachnoid hemorrhage, traumatic brain injury and cerebral ischemia/reperfusion injury [9, 11-15]. Animal safety studies, including skin and eye irritation, dermal sensitization, subchronic, oncogenicity, reproductive toxicity and genotoxicity, were also conducted with resveratrol $[16,28]$, and no adverse event or reproductive toxicity were observed after the trans-resveratrol treatment in animal models $[29,30]$. In the present study we failed to find any adverse effects of resveratrol on normal rats. The characteristics of being well-tolerated and low toxicity characteristics have led resveratrol to be applied in many recent clinical trials [20-22]. Furthermore, several studies have investigated the drug's effects on the central nervous system in human adults [23, 31]. Potential adverse effects of resveratrol treatment have also been tested in humans, and no adverse events have been reported in the majority of the studies $[24,55,58]$. Therefore, we believe that resveratrol could be safe for neonatal hypoxicischemic brain injury. To the best of our knowledge, only a couple of studies $[24,25,55,58]$ have ever reported a neuroprotective role for resveratrol in a model of neonatal hypoxic-ischemic brain injury, which showed that pretreatment with resveratrol reduced brain damage, leading us to realize the preventative power of resveratrol. The neuroprotective studies of post-treatment with resveratrol were performed in acute brain injury models, and the other agents were found neuroprotective in the neonatal rat after hypoxic-ischemic injury [32-37]. A recently comprehensive study indicated a neuroprotection in adult brain of nonhuman primates after a long-term of resveratrol supplementary [38]. Thus, we further characterized the underlying mechanisms of the protective effect of post-treatment with resveratrol.

The general observations in the present study indicate that resveratrol may improve the brain's recovery at multiple levels. Further, Nissl and MAP-2 staining were used to identify whether neurons underwent pathological changes, and the results suggest that neuronal structure and function was maintained after administration with resveratrol. MBP staining revealed the protective effect of resveratrol on white matter. The apparent tissue loss and neuronal death at 7 days in the HI group indicate that the immature brain is unable to repair itself from this injury; however, resveratrol may preserve the structure and morphology of injured tissues and prevent dysfunction in the affected neurons. In contrast to Arteaga1 et al. [25], we found that increasing both the dosage and the treatment duration of resveratrol could improve its effectiveness.

The accumulated evidence indicates that neonatal hypoxic-ischemic brain injury is progressive and that the resulting neuropathies are linked to the activation of neuroinflammatory processes. Resveratrol has been reported to have an anti-inflammatory function and to improve the outcome of several diseases [39]. Our studies found that the inflammatory effect does contribute to 
the model of neonatal hypoxic-ischemic brain injury. The inflammatory response after injury is characterized by increased expression of inflammatory factors at both the RNA and protein levels [40-45]. Our experiments identified the significant expression of these inflammatory factors in the hippocampus and cortex, and further
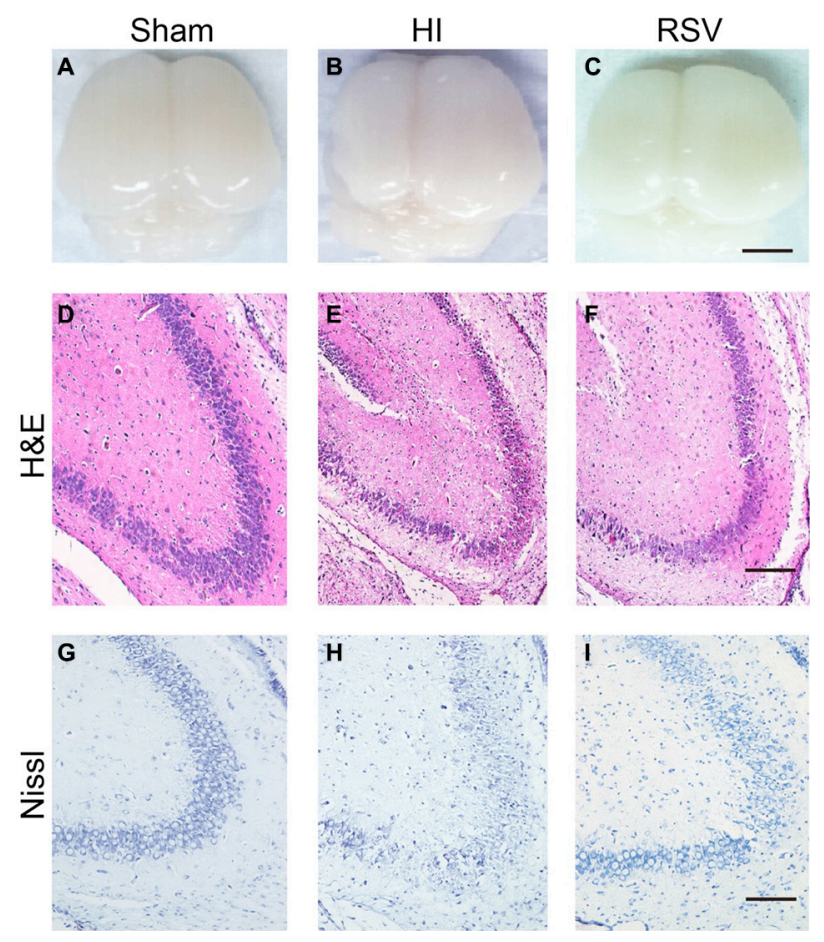

Figure 1: General morphology of the brain and hippocampus after hypoxic-ischemic injury. (A-C) General observation of rat brains 7-day after hypoxic-ischemia from the (A) Sham, (B) HI and (C) RSV. Scale bar = $1 \mathrm{~cm}$. (D-F) Representative photomicrographs of hematoxylin and eosin (H\&E) stained hippocampal dentate gyrus from (D) Sham, (E) HI and (F) RSV groups at 7 days after hypoxicischemia. Scale bar $=200 \mu \mathrm{m}$. (G-I) Representative microphotoimages of Nissl stained dentate gyrus from (G) Sham, (H) HI and (I) RSV rats at 7-day after the HI injury. Scale bar $=100 \mu \mathrm{m}$.
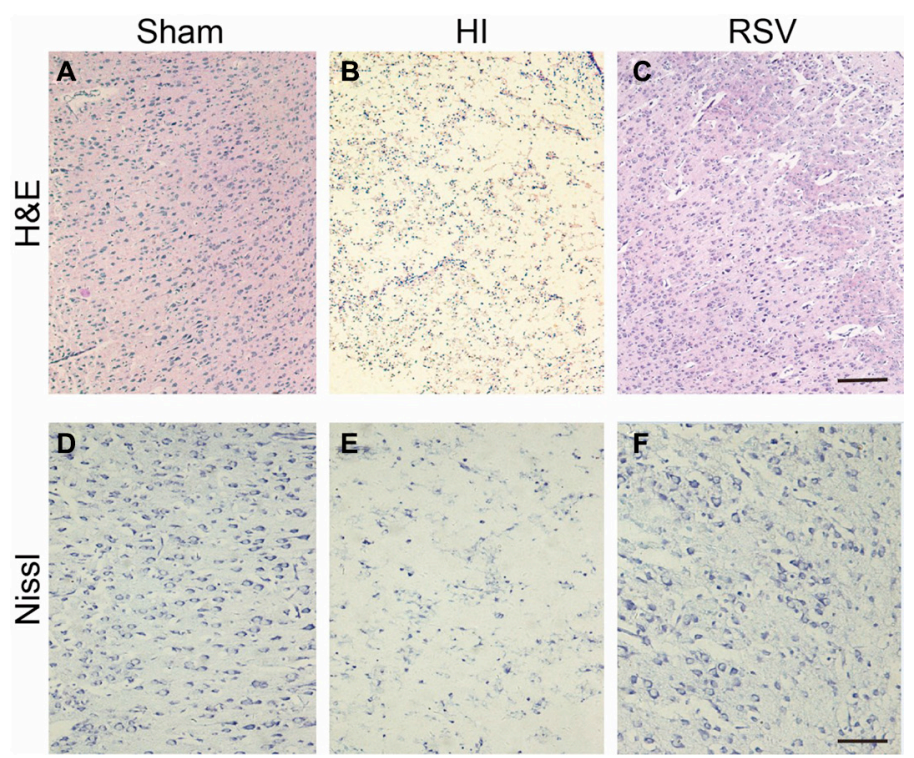

Figure 2: General morphology of the cortex after hypoxic-ischemia. (A-C) Representative microphotographs of hematoxylin and eosin (H\&E) stained cortex from (A) Sham, (B) HI and (C) RSV at 7-day after hypoxic-ischemic insult. Scale bar = $200 \mu$ m. (D-F) Representative photomicrographs of Nissl stained cortex from (D) Sham, (E) HI and (F) RSV animals at 7-day after the injury. Scale bar $=100 \mu \mathrm{m}$. 
demonstrated that resveratrol plays a protective role in the inflammatory cascade by inhibiting their mRNA expression and protein production. Cytokines in the CNS are primarily derived from immune cells. Microglia are a major component of the immune cells in the CNS and strongly activated in the neonatal brain [3, 44, 46, 47]. When an ischemic event occurs, microglia are activated, and they release inflammatory factors leading to the deterioration of the injury. We did find that the IBA-1like immunoreactive signal was deceased following the resveratrol, indicating that resveratrol attenuated the activation of microglia, and suggesting that the decreased inflammatory cytokines partly derives from suppression of activated microglia. However, considering M1/M2 phenotypes switching and balance [48-50], it would be interesting to further determine the microglia/macrophage M1 and/or M2 phenotypes in the hypoxic-ischemia brain.

Apoptosis is another critical event in hypoxicischemic brain injury. Previous studies shown that many apoptosis-related factors, such as caspase-3, Apaf-1,
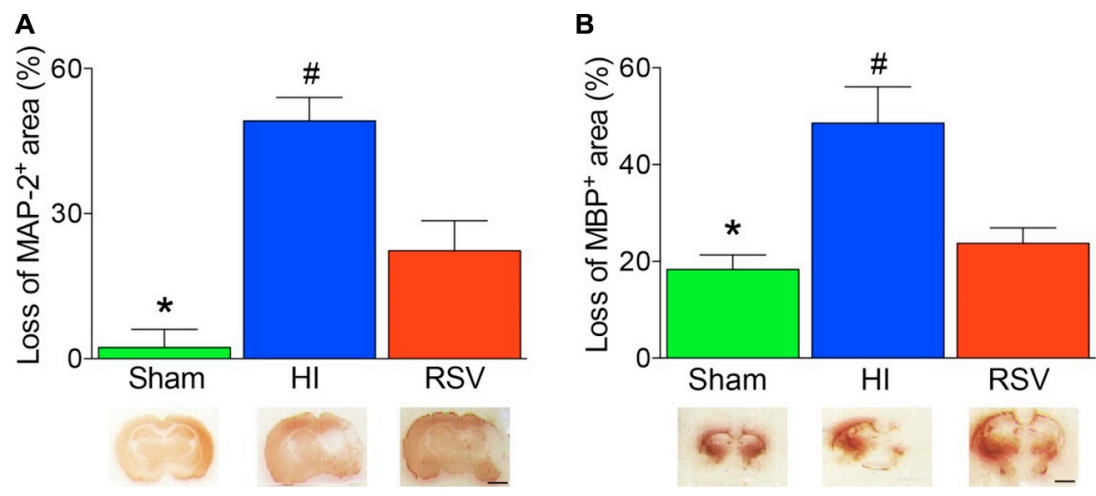

Figure 3: Lesion size with MAP-2 and MBP staining after hypoxic-ischemic injury. The loss of MAP-2 (A) and MBP (B) areas were significantly higher in the HI group than in the groups of Sham or RSV. Representative examples of coronal sections at 7 day after hypoxic-ischemia were shown in the lower panels accordingly. Values are mean \pm SEM, $n=4$ animals per group. Sham vs. RSV, $* p<0.05$; HI vs. Sham or RSV, ${ }^{*} p<0.05$.

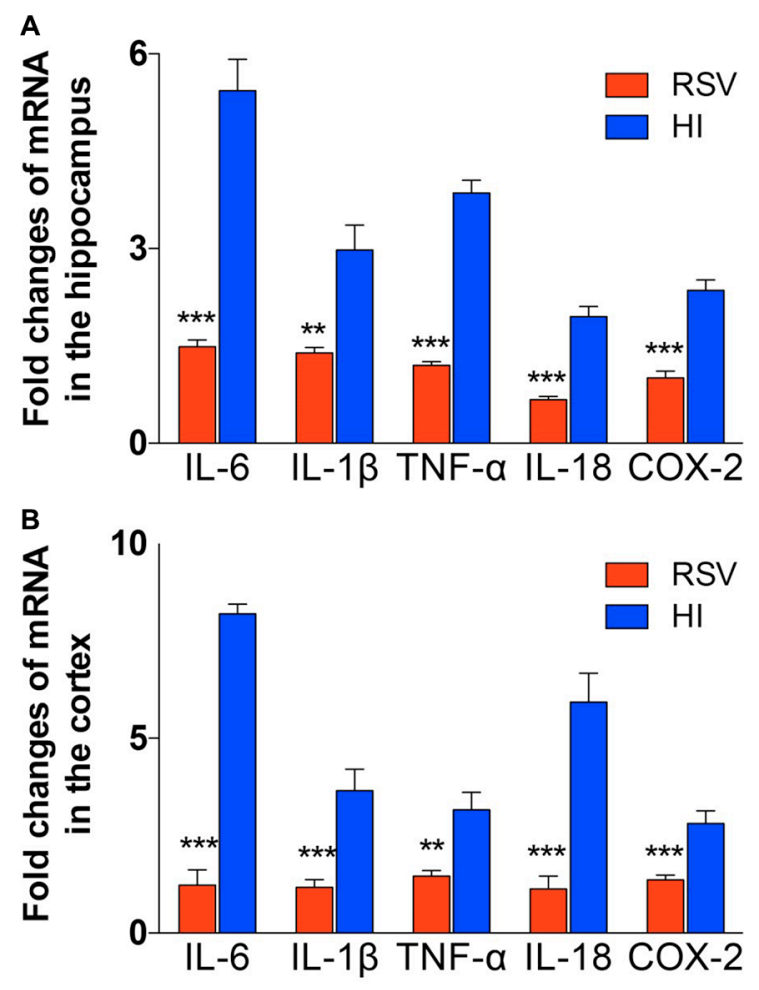

Figure 4: The exprestsion of inflammatory response genes in hippocampus and cortex. The levels of mRNA expression in hippocampus (A) and cortex (B) $24 \mathrm{~h}$ after hypoxic-ischemic injury are reported as the value normalized to $\beta$-Actin for each sample. Values are mean $\pm \mathrm{SEM}, n=5$ animals per group. HI vs. RSV, $* * p<0.01, * * * p<0.001$. 
Bcl-2 and Bax, are normally expressed at a high level in the immature brain [7], showing that apoptosis is more prominent in the immature brain than the adult $[51,52]$. Resveratrol has been reported to have an anti-apoptotic activity $[10,53]$, We asked whether an anti-apoptotic effect contributes to the protective role of post-treatment with resveratrol in neonatal HI. Bax-dependent mitochondrial outer membrane permeabilization is a critical event in the apoptotic mechanism that occurs in the immature brain $[25,46,54]$. After HI, Bax translocates from the cytosol to the mitochondrial outer membrane and forms pores, leading to mitochondrial permeabilization followed by activation of apoptotic cell death [46]. Bax-inhibiting peptide has a neuroprotective effect on neonatal hypoxicischemic brain injury [54], but not the corresponding injury in adult [47], showing the crucial role of Bax in the apoptotic mechanism after neonatal hypoxicischemic brain injury. Caspase- 3 is a critical executioner of apoptosis. The caspase-dependent pathway for the induction of apoptosis converges upon the activation of caspase- 3 . The extent of caspase- 3 cleavage and activation following brain injury is greater in developing rodents compared to adults [4]. Therefore, Bax and caspase-3 have become the main focus in apoptosis studies. In our experiments, DNA fragmentation, the expression of Bax and cleaved caspase 3 were inhibited by resveratrol, suggesting that resveratrol suppresses the initiation of apoptosis to some extent. Bcl-2, which has been reported to be involved in mechanisms other than those based on direct interaction with Bax, was elevated by resveratrol
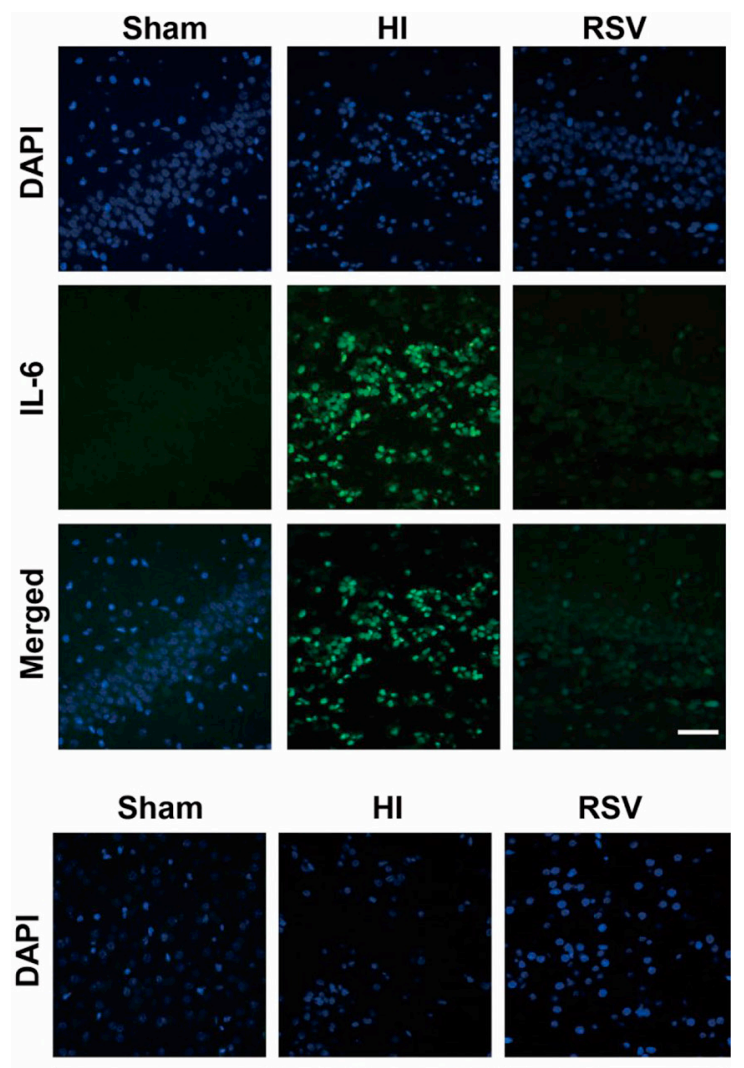

RSV
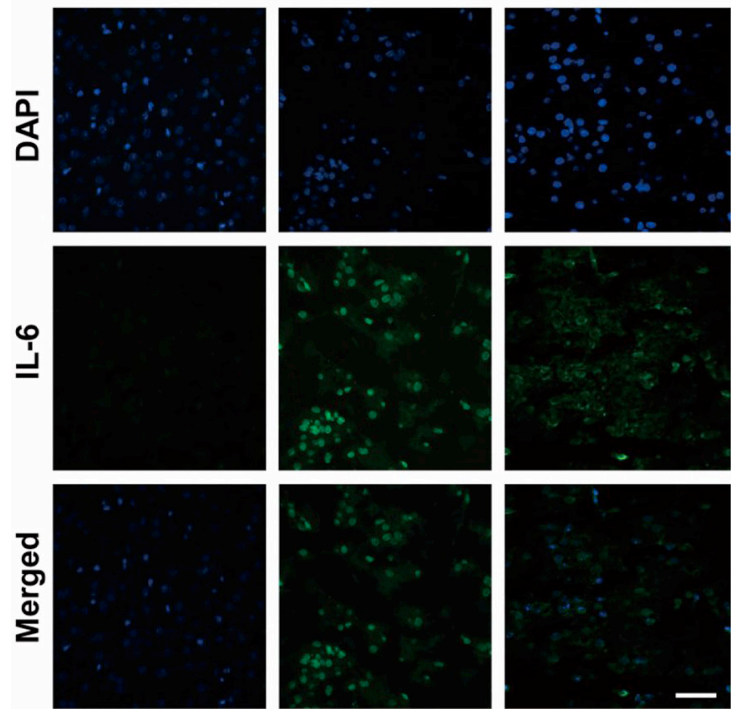

Figure 5: IL-6 immunohistochemistry. Representative examples of microphotographs from 7 days after hypoxic-ischemia in the hippocampal dentate gyrus (A) and cortex (B). Note that the IL-6 immunoreactive signals were significantly increased in the HI group compared to the Sham, and decreased after post-treatment with RSV. Scale $=100 \mu \mathrm{m}$. 
leading to an anti-apoptotic effect. The anti-apoptotic effect of resveratrol may contribute to the recovery of brain tissue and neuronal function.

Overall, to evaluate the potential neuroprotection of resveratrol after neonatal hypoxic-ischemic brain injury, we examined the histological changes in the brain. We observed that resveratrol promotes the recovery of tissue loss and has an anti-inflammatory role by inhibiting the injury-induced up-regulation of inflammatory factors at the mRNA and protein levels. Further, we found that resveratrol decreases DNA fragmentation, the protein expression of Bax and caspase 3 cleavage and increases

A

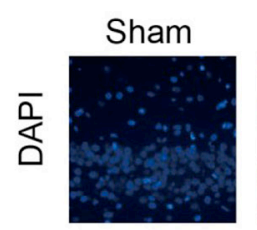

$\mathrm{HI}$

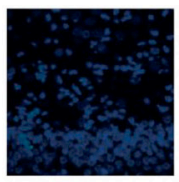

RSV
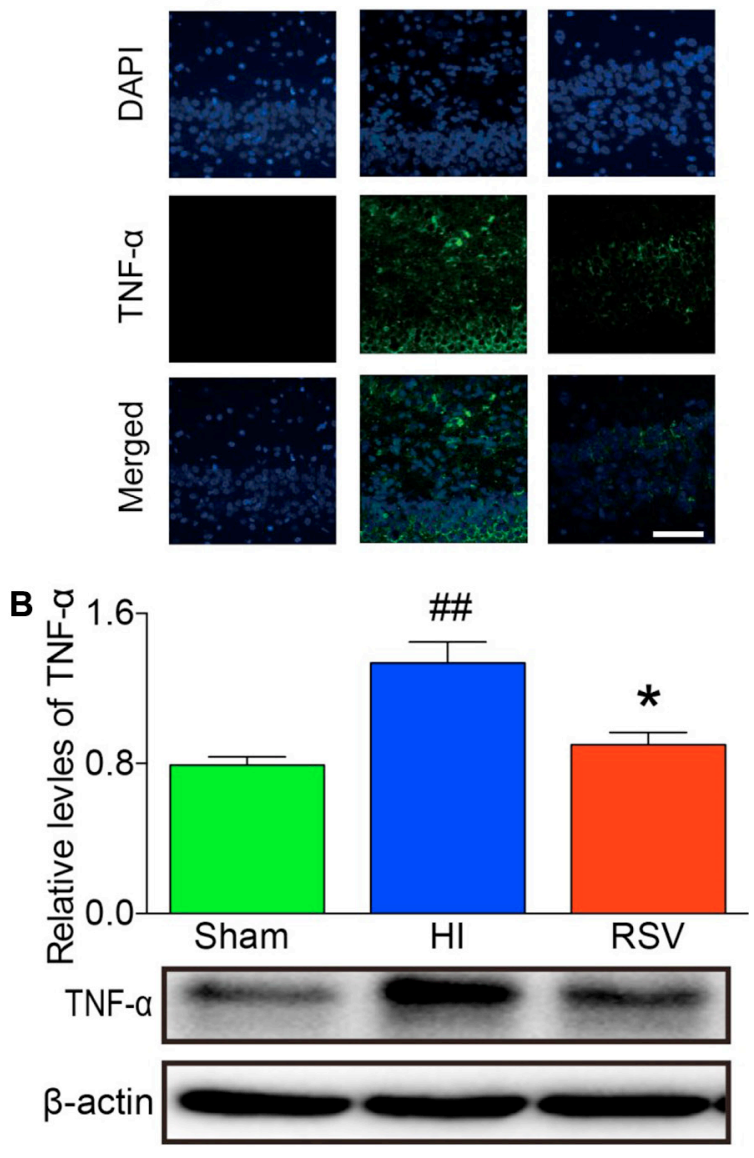

C

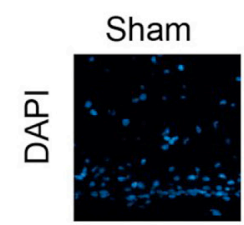

\section{$\mathrm{HI}$}

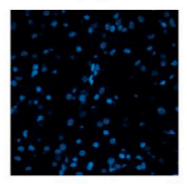

RSV
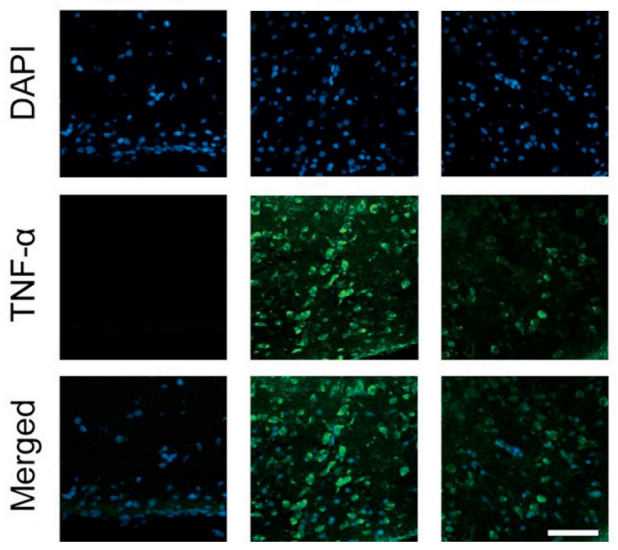

Figure 6: TNF- $\boldsymbol{\alpha}$ immunohistochemistry and Western blots. Representative examples of microphotographs from 7 days after hypoxic-ischemia in the hippocampal dentate gyrus (A) and cortex (C). (B) Western blot analysis of TNF- $\alpha$ levels in the hippocampus. $\beta$-Actin served as a protein loading control. The protein TNF- $\alpha$ contents were significantly lower in hippocampus of the RSV animals 7 days after hypoxic-ischemia than the HI animals (upper panel B). Representative Western blot detected with anti-TNF- $\alpha$ antibody (lower panel B). Scale $=100 \mu \mathrm{m}$. Values are mean $\pm \mathrm{SEM}, n=5$ rats per group. RSV vs. HI, ${ }^{*} p<0.05$; Sham vs. HI, ${ }^{\# \#} p<0.01$. 

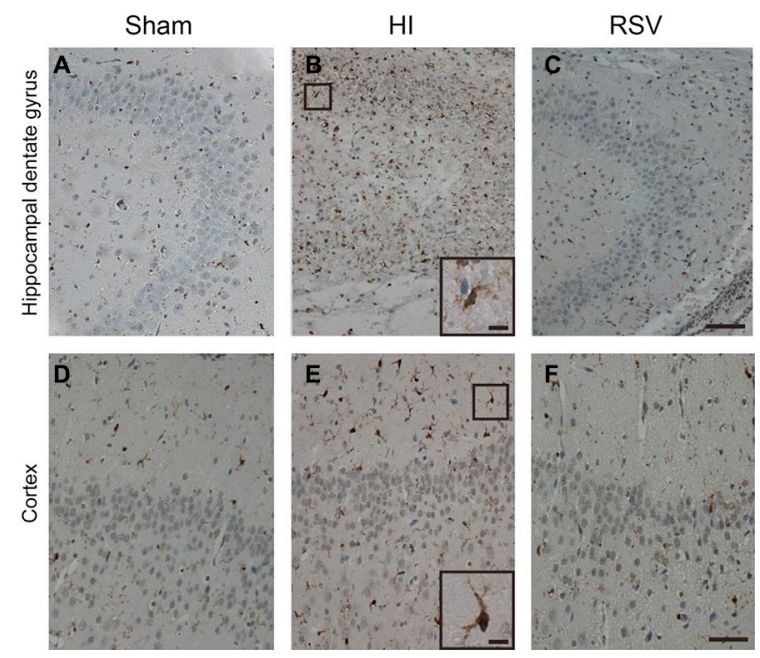

Figure 7: Iba-1 immunohistochemistry. Representative examples of photomicrographs from 7 day after hypoxic-ischemia in the hippocampal dentate gyrus (B) and cortex (E). Note that the Iba-1 immunoreactive signals were significantly increased in the HI (B, E) group compared to the Sham (A, D), but decreased after post-treatment with RSV $(\mathbf{C}, \mathbf{F})$. Insets: Higher magnification of Iba-1 positive cells from dentate gyrus and cortex in the HI group. Scale $=100 \mu \mathrm{m}(\mathrm{A}-\mathrm{F})$ and $25 \mu \mathrm{m}$ (insets).
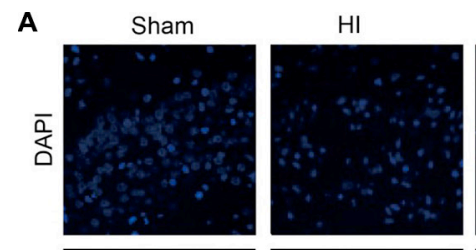

\section{RSV}
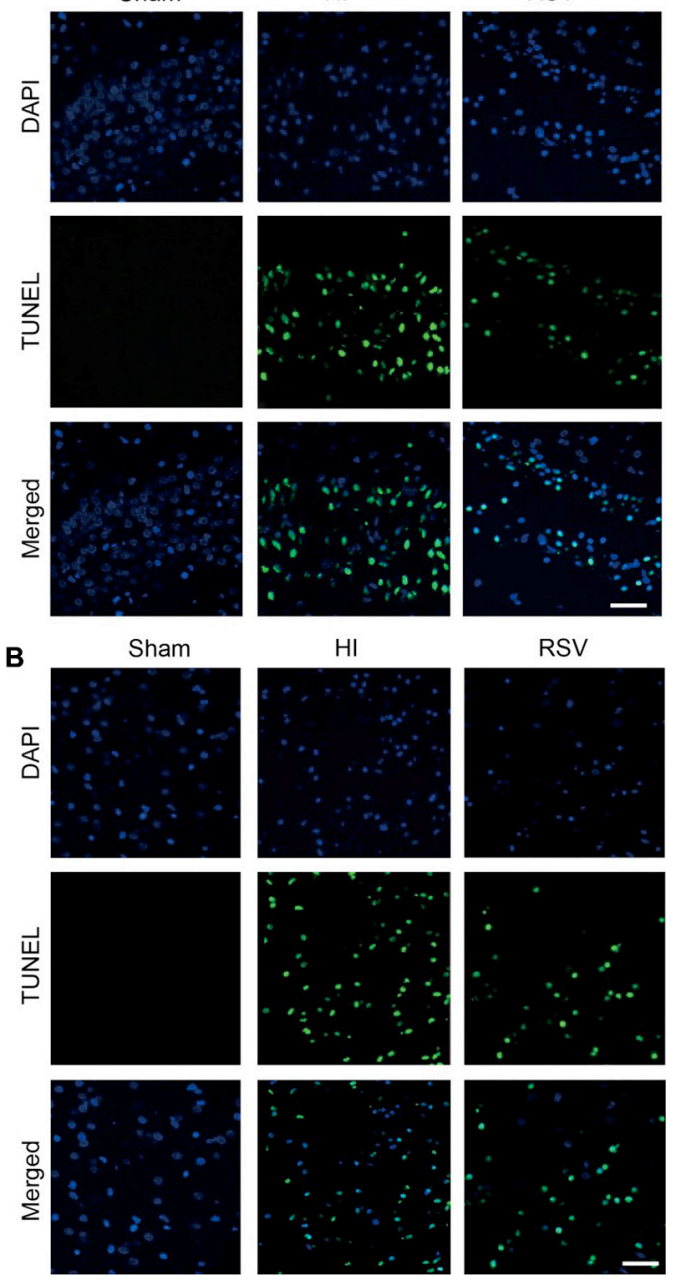

Figure 8: TUNEL immunohistochemistry. Representative examples of microphotographs from 7 day after hypoxic-ischemia in the hippocampal dentate gyrus (A) and cortex (B). Note that the TUNEL immunoreactive signals were significantly increased in the HI group versus the Sham, and decreased after post-treatment with RSV. Scale $=100 \mu \mathrm{m}$. 
Bcl-2 expression. The decreased tissue loss might be due to the protective role of resveratrol in inhibiting inflammation and apoptosis during the acute interval after injury. Thus we identified the neuroprotective role for posttreatment with resveratrol against the neonatal hypoxicischemic brain injury. We also found that the protective role and potential therapeutic value of resveratrol for treating neonatal HI brain injury was associated with anti-inflammatory and anti-apoptotic mechanisms. It is noted that current study was carried out with one single dose of resveratrol application. Since neonatal hypoxicischemic brain injury is a complicated injury, and targeting only one mechanism is far from sufficient, exploring the timing, dosage and routes of the drug administration, the relationship between apoptosis and inflammation, and the functional studies should be addressed in the future.

A
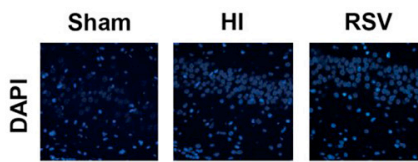

B
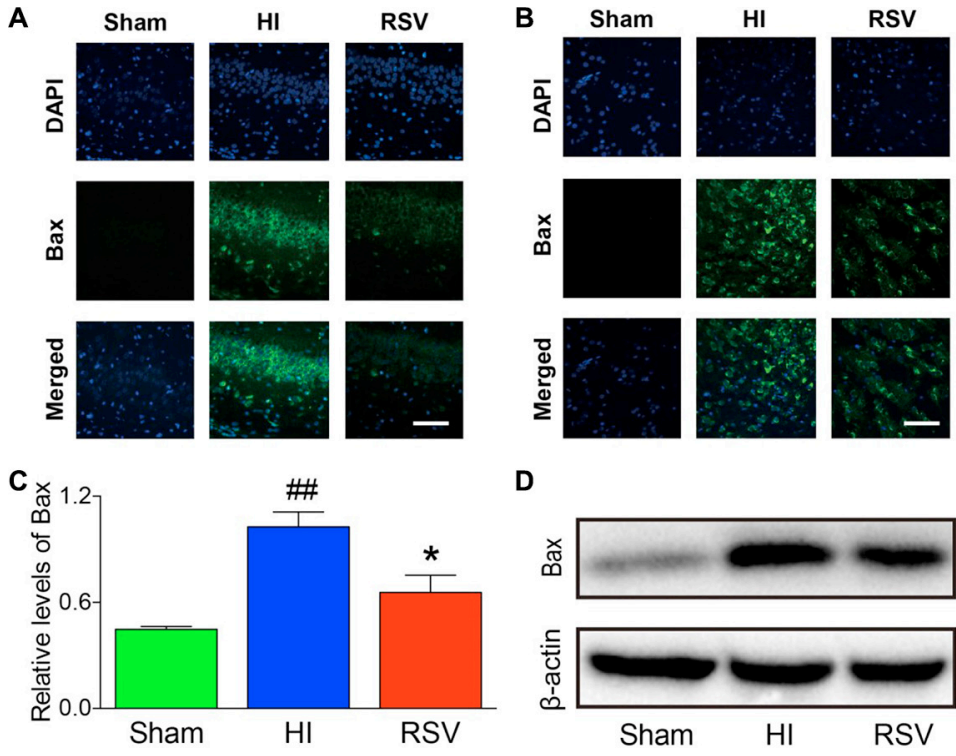

D

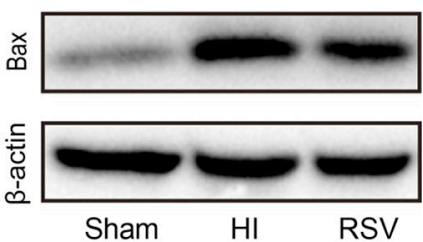

Figure 9: Bax immunohistochemistry and Western blots. Representative examples of microphotographs from 7 days after hypoxic-ischemia in the hippocampus (A) and cortex (B). (C) Western blot analysis of Bax levels in the hippocampus. $\beta$-Actin served as a protein loading control. The protein Bax contents were significantly lower in hippocampus of the RSV animals 7 days after hypoxicischemia than the HI animals. (D) Representative Western blot detected with anti-Bax antibody. Scale $=100 \mu \mathrm{m}$. Values are mean $\pm \mathrm{SEM}$, $n=5$ rats per group. RSV vs. HI, ${ }^{*} p<0.05$; Sham vs. HI, ${ }^{\#} p<0.01$.
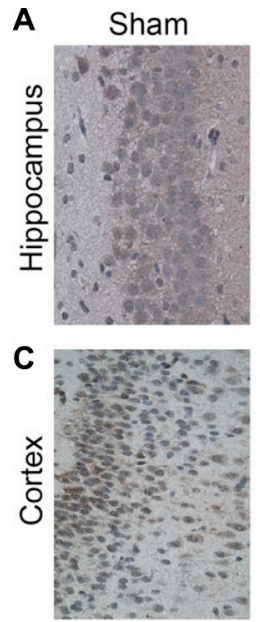

$\mathrm{HI}$
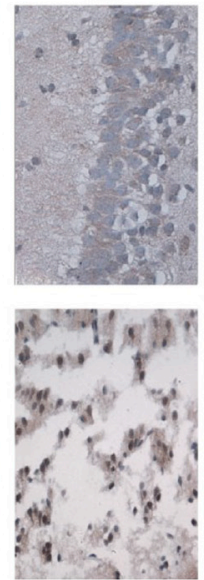

RSV
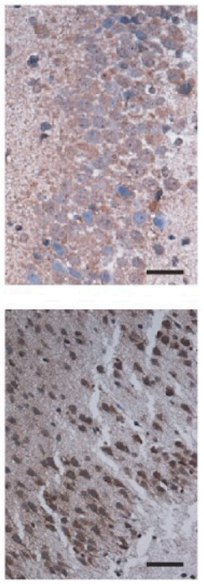

B

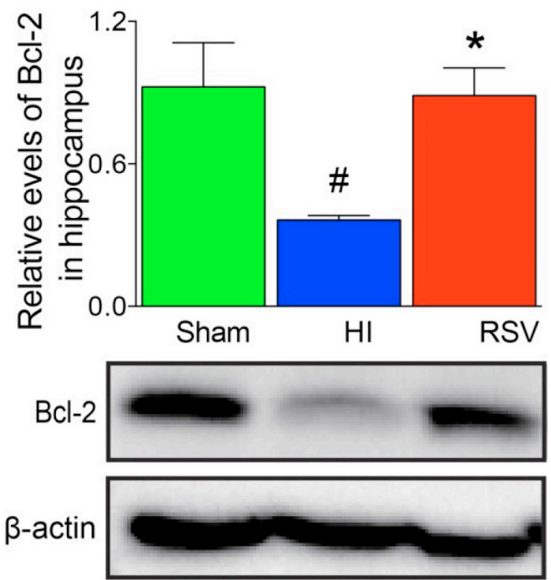

Figure 10: Bcl-2 immunohistochemistry and Western blots. Representative examples of microphotographs from 24 hours after hypoxic-ischemia in the hippocampal CA3 (A) and cortex (C). (B) Western blot analysis of Bcl-2 levels in the hippocampus. $\beta$-Actin served as a protein loading control. The protein Bcl-2 contents were significantly higher in hippocampus of the RSV animals 24 hours after hypoxic-ischemia than the HI animals (upper panel B). Representative Western blot detected with anti-Bcl-2 antibody (lower panel B). Scale $=50 \mu \mathrm{m}$. Values are mean $\pm \mathrm{SEM}, n=5$ rats per group. RSV vs. HI, ${ }^{*} p<0.05$; Sham vs. HI, ${ }^{\#} p<0.05$. 


\section{MATERIALS AND METHODS}

\section{Rat model of HI injury and RSV administration}

All animal procedures were performed in accordance with the Animal Center of the Chinese Academy of Science (Shanghai, China) and the Laboratory Animal Ethics Committee of Wenzhou Medical University. Efforts were made to minimize animal suffering and to minimize the number of animals used. Pregnant rats (Sprague-Dawley) were purchased from the Animal Center of the Chinese Academy of Sciences and were housed individually, maintained on an ad libitum feeding schedule, and kept on a 12-h light/dark cycle. The hypoxiaischemia (HI) model was produced on postnatal day 7 (P7) rat litters as described [55] with modification. Briefly, pups were anesthetized with 3\% isoflurane and the balance of room air, and the left common carotid artery was ligated. The rats were sutured, $1.5 \mathrm{~h}$ for recovery, and placed in a glass chamber containing a humidified atmosphere of $8 \%$ oxygen $/ 92 \%$ nitrogen, which was submerged in a $37.5^{\circ} \mathrm{C}$ water bath to maintain normothermia. Pups were kept in hypoxic chambers for $2.5 \mathrm{~h}$ and then returned to their dam. A sham group that had a ligature placed in an identical fashion without actually occluding the vessel or without undergoing hypoxia serviced as controls. Resveratrol (Sigma Chemical Co., UK) was freshly prepared by
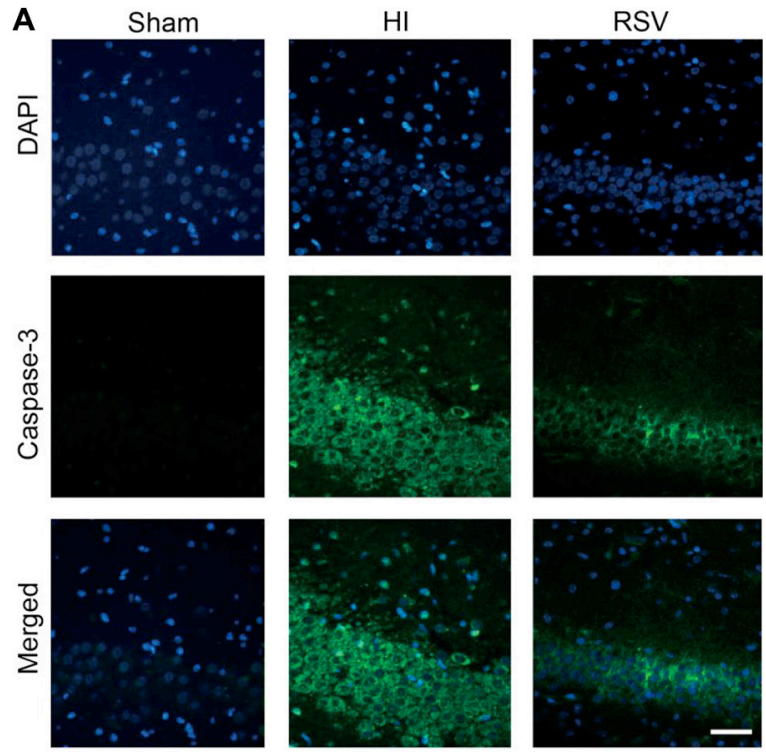
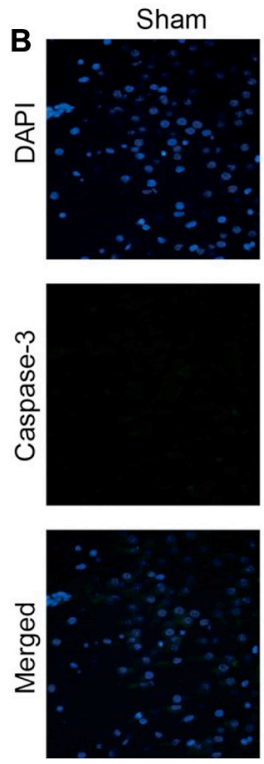

$\mathrm{HI}$
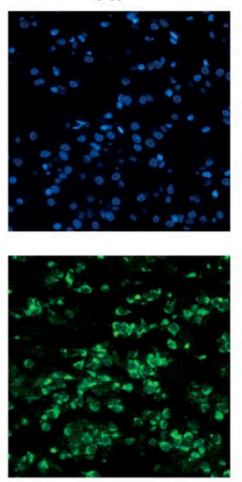

RSV
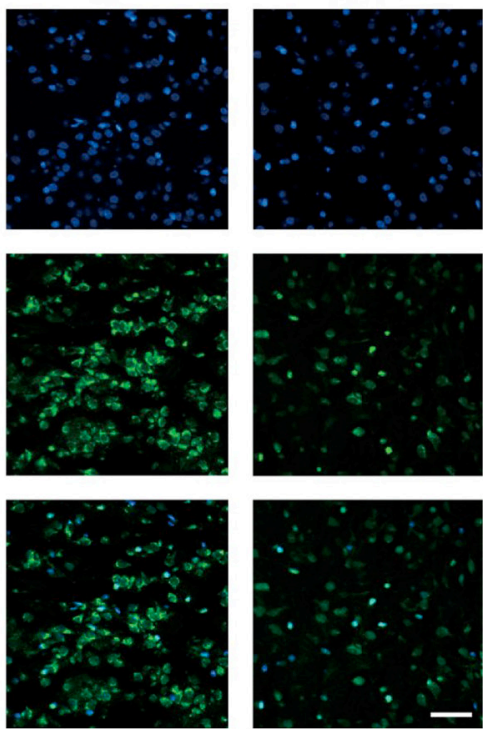

Figure 11: Caspase-3 immunohistochemistry. Representative examples of microphotographs from 24 hours after hypoxic-ischemia in the hippocampal dentate gyrus (A) and cortex (B). Note that the Caspase-3 immunoreactive signals were significantly increased in the HI group compared to the Sham, and decreased after the RSV post-treatment. Scale $=100 \mu \mathrm{m}$.versus the Sham, and decreased after posttreatment with RSV. Scale $=100 \mu \mathrm{m}$. 
dissolving and diluting in $2 \%$ ethanol. Resveratrol $(100 \mathrm{mg} / \mathrm{kg}$, i.p.) was injected three times at $0 \mathrm{~h}, 8 \mathrm{~h}$ and $18 \mathrm{~h}$, respectively, after hypoxic-ischemic brain injury (groups of HI plus resveratrol) [56, 57], while the HI group received $2 \%$ ethanol alone (i.p.) and the volume of the $2 \%$ ethanol was calculated by using the following equation: $(100 \times$ the amount of all pups in the HI group $\times$ the weight of the pup in the sham group)/ total weight of the pups in the HI group. These rats were sacrificed at $24 \mathrm{~h}$ after the injury and performed experiments for detecting message and protein levels of anti-inflammatory factors, and immunohistochemistry signal of Iba-1, Bcl-2, Bax, and caspase 3, respectively. Those brains collected at $7 \mathrm{~d}$ post-injury for general observation, H\&E, and signal of MBP/MAP-2 were received two additional injections of resveratrol $(100 \mathrm{mg} / \mathrm{kg}$, i.p.) at $48 \mathrm{~h}$ and $72 \mathrm{~h}$ following the hypoxicischemic injury.

\section{Histochemistry and immunohistochemistry}

Rats were deeply anesthetized and transcardially perfused with $20 \mathrm{ml}$ of saline, then with $20 \mathrm{ml}$ of $4 \%$ paraformaldehyde (PFA) in $1 \times$ phosphate buffered saline (PBS) for 5 min. Brains were removed and kept in $4 \%$ PFA for a post-fix overnight. After dehydration the brains were embedded in paraffin, and sliced coronally in 5- $\mu \mathrm{m}$. Tissue sections were initially subjected to hematoxylin and eosin (HE) staining and Nissl staining for general assessment of histopathology.

Additional sets of sections were dewaxed in xylene overnight and subsequently passed through $3 \times 10 \min 99 \%$ ethanol and $2 \times 10$ min $96 \%$ ethanol. Endogenous peroxidase activity was then blocked with $0.35 \% \mathrm{H}_{2} \mathrm{O}_{2}\left(35 \% \mathrm{H}_{2} \mathrm{O}_{2}\right.$ diluted 1:99 in methanol) for 30 min. Rehydration was completed by a rinse in $96 \%$ ethanol, $10 \mathrm{~min}$ in $70 \%$ ethanol and 3 rinses in distilled water, and then incubated with $5 \%$ bovine serum albumin (BSA) for $30 \mathrm{~min}$ at room temperature. Antibodies (Bcl-2, sc-492, 1:150, Santa Cruz Biotechnology; Iba-1, 1:400, ab5076, Abcam; MAP-2, 1:200, sc-20172, Santa Cruz Biotechnology; MBP, 1:200, sc-13914, Santa Cruz Biotechnology; TNF- $\alpha, 5 \mu \mathrm{g} / \mathrm{ml}$, ab9755, Abcam; IL-6,1:200, sc-1266, Santa Cruz Biotechnology; Bax, 1:200, sc-493, Santa Cruz Biotechnology and cleaved caspase 3, 1:400, \#9579, Cell Signaling Technology) were diluted in $10 \mathrm{mM}$ PBS containing $0.1 \%$ BSA, $0.3 \%$ Triton $\mathrm{X}-100$, respectively, and the sections were incubated with the primary antibodies overnight for $1 \mathrm{~h}$ at RT and subsequently at $4{ }^{\circ} \mathrm{C}$ overnight. The horseradish peroxidase (HRP) conjugated secondary antibodies were incubated at room temperature for $1 \mathrm{~h}$, followed by 3,3'-diaminobenzidine (DAB) staining (Bcl-2, Iba-1 MAP-2, MBP and IL-6), or incubation of the Alexa Fluor
488 conjugated secondary antibodies (TNF- $\alpha$, IL-6, Bax and cleaved caspase 3 ). Negative controls were performed using the same procedure described above in the absence of the primary antibody. The tissues were counterstained with DAPI, mounted with Anti-fade Mounting Medium. The images of MAP-2 and MBP were captured with a scanner (imageCLASS MF4322d, Canon) and others were visualized using a Nikon ECLIPSE Ti microscope (Nikon, Tokyo, Japan). The extent of tissue damage was determined by calculating the amount of surviving tissue in each section. Briefly, brain damage was analyzed using the ImageJ software (http://imagej.nih.gov/ij/) by outlining both hemispheres on full section images. The ipsilateral MAP-2 area was calculated as a percentage for each animal using the following equation: [1 - (area ipsilateral MAP-2 staining/area contralateral MAP-2 staining) $] \times 100$. The MBP area was determined as same as the calculation method of the MAP-2 area loss. For TUNEL (terminal deoxynucleotidyltransferase-mediated dUTP nick end labeling) staining, sections were incubated with TUNEL reaction mixture in a dark humidified chamber for $1 \mathrm{~h}$ at $37^{\circ} \mathrm{C}$, followed by a final wash for $3 \times 10$ min with PBS. Apoptotic cells were characterized by green fluorescence of the nucleus and nuclear membrane according to the manufacturer's protocol. Quantitation was performed by counting the number of positive cells in five randomly chosen fields within each slide at $400 \times$ magnification using a Nikon ECLIPSE Ti microscope. The index of apoptosis was calculated as the ratio of the overall number of apoptotic cells to the total number of cells.

\section{Quantitative real-time RT- PCR}

Cohorts of animals were decapitated, the brains rapidly removed and cortex dissected free on an ice block, frozen in liquid nitrogen and stored at $80^{\circ} \mathrm{C}$. The tissue samples were homogenized in TRIzol reagent (TriPure Isolation Reagent, Roche Applied Science). Total RNA was extracted from the tissue according to the manufacturer's protocol. The extracted RNA was quantified by UV spectrophotometry; only those samples with a 260:280 ratio of greater than 1.8 were used. Total RNA was reverse transcribed in duplicate. A third RNA sample was incubated without reverse transcriptase (noRT control). Totally $0.5 \mu \mathrm{g}$ of RNA was used to synthesize the cDNA using the Prime Script ${ }^{\mathrm{TM}}$ RT reagent Kit and Bio-Rad MyCycler TM ${ }^{\mathrm{TM}}$ Thermal Cycler for the reverse transcription polymerase chain reaction. Samples were run in parallel with each primer set in real-time PCR with bio-radiQ ${ }^{\mathrm{TM}} \mathrm{SYBR}^{\circledR}$ Green Supermix. $\beta$-actin serviced as a housekeeping control. The forward and reverse primer sequences are shown in Table 1. The specificity of each PCR reaction was determined with melting curve analysis, which is a measure of product length and GC composition 
Table 1: Primers used in the studies

\begin{tabular}{lll}
\hline Gene & Forward primers & Reverse primers \\
\hline COX-2 & CGGAGGAGAAGTGGGGTTTAGGAT & TGGGAGGCACTTGCGTTGATGG \\
IL-18 & AAACCCGCCTGTGTTCGA & TCAGTCTGGTCTGGGATTCGT \\
IL-1 $\beta$ & CACCTCTCAAGCAGAGCACAG & GGGTTCCATGGTGAAGTCAAC \\
IL-6 & GAGTTGTGCAATGGCAATTC & ACTCCAGAAGACCAGAGCAG \\
TNF- $\alpha$ & TACTCCCAGGTTCTCTTCAAGG & GGAGGCTGACTTTCTCCTGGTA \\
$\beta-$ Actin & AAGTCCCTCACCCTCCCAAAAG & AAGCAATGCTGTCACCTTCCC \\
\hline
\end{tabular}

and provides a melting temperature that is specific for each amplicon [58]. To further refine the measurement of PCR amplification in this process, the amplification signal for each PCR reaction was measured at a temperature set below the melting point for the amplicon, but above any non-specific fluorescent signal in the reaction. The crossing point for the gene of interest was normalized for the efficiency of each primer set at that PCR cycle length using efficiency curves generated by serial dilution of RNA standards with each primer set, and to the crossing point for $\beta$-actin for each sample [59].

\section{Western blot}

Brain tissues were lysed in RIPA buffer $(25 \mathrm{mM}$ Tris- $\mathrm{HCl}, 150 \mathrm{mM} \mathrm{NaCl}, 1 \%$ Nonidet P-40, $1 \%$ sodium deoxycholate, and $0.1 \%$ sodium dodecyl sulfate) with supplemental protease and phosphatase inhibitors (GE Healthcare Biosciences, Piscataway, NJ, USA). After centrifugation, the extracts above were quantified with bicinchoninic acid (BCA) reagents (Thermo, Rockford, IL, USA). The complex was then centrifuged at 12,000 $\mathrm{rpm}$, and the supernatant was obtained for the protein assay. Proteins (30 $\mu \mathrm{g}$ for TNF- $\alpha, \mathrm{Bcl}-2$, and Bax) were subjected to sodium dodecyl sulfate polyacrylamide gel electrophoresis (SDS-PAGE) using 12\% gels and blotted on to nitrocellulose membranes. After blocking, membranes were incubated with primary antibody (TNF- $\alpha$, 1:3000, ab9755, Abcam; Bcl-2, 1:1000, \#2876, Cell Signaling; Bax, 1:200, sc-493, Santa Cruz Biotechnology). Then, horseradish peroxidase-conjugated secondary antibodies (1:3000) were incubated with the blots for $1 \mathrm{~h}$ at room temperature. Western blotting of $\beta$-actin $(1: 3000$, Bioworld, AP0060) was performed to demonstrate equal protein loading, and used as an internal control. Western blots were scanned and quantified through optical density measurements by ChemiDoc XRS+ Imaging System (Bio-Rad). Each sample was analyzed in 2 or 3 times in independent experiments, and the densitometric values of the bands on the western blots acquired by the Image Lab software (BioRad).

\section{Statistical analysis}

Student's $t$ test or factorial analysis of variance with Tukey post hoc comparisons was performed (GraphPad
Prism 5). Results are shown as the mean \pm SEM. $P<0.05$ indicated a significant difference.

\section{ACKNOWLEDGMENTS AND FUNDING}

This study was partially supported by the State Key Basic Research Development Program (2012CB518105), Wenzhou Science \& Technology Bureau Program (Y20140681), and National Natural Science Foundation of China (81472165, 81300311 and 81671229).

\section{CONFLICTS OF INTEREST}

None.

\section{REFERENCES}

1. Davidson JO, Wassink G, van den Heuij LG, Bennet L, Gunn AJ. Therapeutic Hypothermia for Neonatal HypoxicIschemic Encephalopathy - Where to from Here? Front Neurol. 2015; 6:198. doi: 10.3389/fneur.2015.00198.

2. Algra SO, Groeneveld KM, Schadenberg AW, Haas F, Evens FC, Meerding J, Koenderman L, Jansen NJ, Prakken BJ. Cerebral ischemia initiates an immediate innate immune response in neonates during cardiac surgery. J Neuroinflammation. 2013; 10:24. doi: 10.1186/17422094-10-24.

3. Liu F, McCullough LD. Inflammatory responses in hypoxic ischemic encephalopathy. Acta Pharmacol Sin. 2013; 34: 1121-30. doi: 10.1038/aps.2013.89.

4. Northington FJ, Chavez-Valdez R, Martin LJ. Neuronal cell death in neonatal hypoxia-ischemia. Ann Neurol. 2011; 69:743-58. doi: 10.1002/ana.22419.

5. Lin WY, Chang $\mathrm{YC}$, Ho CJ, Huang CC. Ischemic preconditioning reduces neurovascular damage after hypoxia-ischemia via the cellular inhibitor of apoptosis 1 in neonatal brain. Stroke. 2013; 44:162-9. doi: 10.1161/ STROKEAHA.112.677617.

6. Zhu C, Wang X, Huang Z, Qiu L, Xu F, Vahsen N, Nilsson M, Eriksson PS, Hagberg H, Culmsee C, Plesnila N, Kroemer G, Blomgren K. Apoptosis-inducing factor is a major contributor to neuronal loss induced by neonatal cerebral hypoxia-ischemia. Cell Death and Differentiation. 2007; 14:775-84. doi. 
7. Zhu C, Wang X, Xu F, Bahr BA, Shibata M, Uchiyama Y, Hagberg H, Blomgren K. The influence of age on apoptotic and other mechanisms of cell death after cerebral hypoxiaischemia. Cell Death Differ. 2005; 12:162-76. doi: 10.1038/ sj.cdd. 4401545 .

8. Singh CK, Liu X, Ahmad N. Resveratrol, in its natural combination in whole grape, for health promotion and disease management. Ann N Y Acad Sci. 2015; 1348:150-60. doi: 10.1111 nyas. 12798 .

9. Fang LQ, Gao HM, Zhang WN, Zhang WJ, Wang YA. Resveratrol alleviates nerve injury after cerebral ischemia and reperfusion in mice by inhibiting inflammation and apoptosis. International Journal of Clinical and Experimental Medicine. 2015; 8:3219-26. doi.

10. Zhou XM, Zhou ML, Zhang XS, Zhuang Z, Li T, Shi JX, Zhang X. Resveratrol prevents neuronal apoptosis in an early brain injury model. Journal of Surgical Research. 2014; 189:159-65. doi: 10.1016/j.jss.2014.01.062.

11. Feng Y, Cui Y, Gao JL, Li MH, Li R, Jiang XH, Tian YX, Wang KJ, Cui CM, Cui JZ. Resveratrol attenuates neuronal autophagy and inflammatory injury by inhibiting the TLR4/NF-kappaB signaling pathway in experimental traumatic brain injury. Int J Mol Med. 2016. doi:10.3892/ ijmm.2016.2495.

12. Lofrumento DD, Nicolardi G, Cianciulli A, De Nuccio F, La Pesa V, CaroFigurelio V, Dragone T, Calvello R, Panaro MA. Neuroprotective effects of resveratrol in an MPTP mouse model of Parkinson's-like disease: possible role of SOCS1 in reducing pro-inflammatory responses. Innate Immun. 2014; 20:249-60. doi: 10.1177/1753425913488429.

13. Ma T, Tan MS, Yu JT, Tan L. Resveratrol as a Therapeutic Agent for Alzheimer's Disease. Biomed Research International. 2014. doi.

14. Maher P, Dargusch R, Bodai L, Gerard PE, Purcell JM, Marsh JL. ERK activation by the polyphenols fisetin and resveratrol provides neuroprotection in multiple models of Huntington's disease. Hum Mol Genet. 2011; 20:261-70. doi: $10.1093 / \mathrm{hmg} / \mathrm{ddq} 460$.

15. Shao AW, Wu HJ, Chen S, Ammar AB, Zhang JM, Hong Y. Resveratrol attenuates early brain injury after subarachnoid hemorrhage through inhibition of NF-kappaB-dependent inflammatory/MMP-9 pathway. CNS Neurosci Ther. 2014; 20:182-5. doi: 10.1111/cns.12194.

16. Horn TL, Cwik MJ, Morrissey RL, Kapetanovic I, Crowell JA, Booth TD, McCormick DL. Oncogenicity evaluation of resveratrol in p53(+/-) (p53 knockout) mice. Food Chem Toxicol. 2007; 45:55-63. doi: 10.1016/j.fct.2006.07.015.

17. Williams LD, Burdock GA, Edwards JA, Beck M, Bausch J. Safety studies conducted on high-purity trans-resveratrol in experimental animals. Food and Chemical Toxicology. 2009; 47:2170-82. doi: 10.1016/j.fct.2009.06.002.

18. Zhu W, Qin W, Zhang K, Rottinghaus GE, Chen YC, Kliethermes B, Sauter ER. Trans-resveratrol alters mammary promoter hypermethylation in women at increased risk for breast cancer. Nutr Cancer. 2012; 64: 393-400. doi: 10.1080/01635581.2012.654926.

19. De Groote D, Van Belleghem K, Deviere J, Van Brussel W, Mukaneza A, Amininejad L. Effect of the intake of resveratrol, resveratrol phosphate, and catechin-rich grape seed extract on markers of oxidative stress and gene expression in adult obese subjects. Ann Nutr Metab. 2012; 61:15-24. doi: 10.1159/000338634.

20. Bashmakov YK, Assaad-Khalil SH, Abou Seif M, Udumyan R, Megallaa M, Rohoma KH, Zeitoun M, Petyaev IM. Resveratrol promotes foot ulcer size reduction in type 2 diabetes patients. ISRN Endocrinol. 2014; 2014:816307. doi: 10.1155/2014/816307.

21. Agarwal B, Campen MJ, Channell MM, Wherry SJ, Varamini B, Davis JG, Baur JA, Smoliga JM. Resveratrol for primary prevention of atherosclerosis: clinical trial evidence for improved gene expression in vascular endothelium. Int J Cardiol. 2013; 166:246-8. doi: 10.1016/j. ijcard.2012.09.027.

22. Kennedy DO, Wightman EL, Reay JL, Lietz G, Okello EJ, Wilde A, Haskell CF. Effects of resveratrol on cerebral blood flow variables and cognitive performance in humans: a double-blind, placebo-controlled, crossover investigation. Am J Clin Nutr. 2010; 91:1590-7. doi: 10.3945/ajcn.2009.28641.

23. Witte AV, Kerti L, Margulies DS, Floel A. Effects of resveratrol on memory performance, hippocampal functional connectivity, and glucose metabolism in healthy older adults. J Neurosci. 2014; 34:7862-70. doi: 10.1523/ JNEUROSCI.0385-14.2014.

24. West T, Atzeva M, Holtzman DM. Pomegranate polyphenols and resveratrol protect the neonatal brain against hypoxicischemic injury. Developmental Neuroscience. 2007; 29:363-72. doi: 10.1159/000105477.

25. Arteaga $\mathrm{O}$, Revuelta M, Uriguen L, Alvarez A, Montalvo H, Hilario E. Pretreatment with Resveratrol Prevents Neuronal Injury and Cognitive Deficits Induced by Perinatal Hypoxia-Ischemia in Rats. Plos One. 2015; 10. doi: ARTN e014242410.1371/journal.pone.0142424.

26. Jin YS, Min AS, Choi EJ, Jin KK, Seo ES, Lee JH, Hai LC, Kim WT. Neuroprotective effects of resveratrol via antiapoptosis on hypoxic-ischemic brain injury in neonatal rats. Korean Journal of Pediatrics. 2008: 1102-11. doi.

27. Dixon BJ, Reis C, Ho WM, Tang JP, Zhang JH. Neuroprotective Strategies after Neonatal Hypoxic Ischemic Encephalopathy. International Journal of Molecular Sciences. 2015; 16:22368-401. doi: 10.3390/ ijms 160922368 .

28. Williams LD, Burdock GA, Edwards JA, Beck M, Bausch J. Safety studies conducted on high-purity transresveratrol in experimental animals. Food Chem Toxicol. 2009; 47:2170-82. doi: 10.1016/j.fct.2009.06.002.

29. Crowell JA, Korytko PJ, Morrissey RL, Booth TD, Levine BS. Resveratrol-associated renal toxicity. Toxicol Sci. 2004; 82:614-9. doi: 10.1093/toxsci/kfh263. 
30. Freyberger A, Hartmann E, Hildebrand H, Krotlinger F. Differential response of immature rat uterine tissue to ethinylestradiol and the red wine constituent resveratrol. Arch Toxicol. 2001; 74:709-15. doi.

31. Renaud J, Martinoli MG. Resveratrol as a protective molecule for neuroinflammation: a review of mechanisms. Curr Pharm Biotechnol. 2014; 15:318-29. doi.

32. Tskitishvili E, Nisolle M, Munaut C, Pequeux C, Gerard C, Noel A, Foidart JM. Estetrol attenuates neonatal hypoxicischemic brain injury. Experimental Neurology. 2014; 261: 298-307. doi: 10.1016/j.expneurol.2014.07.015.

33. Rong Z, Pan R, Chang L, Lee W. Combination treatment with ethyl pyruvate and IGF-I exerts neuroprotective effects against brain injury in a rat model of neonatal hypoxicischemic encephalopathy. Int J Mol Med. 2015; 36:195-203. doi: 10.3892/ijmm.2015.2219.

34. Kim SS, Lee KH, Sung DK, Shim JW, Kim MJ, Jeon GW, Chang YS, Park WS. Erythropoietin attenuates brain injury, subventricular zone expansion, and sensorimotor deficits in hypoxic-ischemic neonatal rats. J Korean Med Sci. 2008; 23:484-91. doi: 10.3346/jkms.2008.23.3.484.

35. Fathali N, Ostrowski RP, Lekic T, Jadhav V, Tong W, Tang J, Zhang JH. Cyclooxygenase-2 inhibition provides lasting protection against neonatal hypoxic-ischemic brain injury. Crit Care Med. 2010; 38:572-8. doi: 10.1097/ CCM.0b013e3181cb1158.

36. Zhou Y, Lekic T, Fathali N, Ostrowski RP, Martin RD, Tang J, Zhang JH. Isoflurane posttreatment reduces neonatal hypoxicischemic brain injury in rats by the sphingosine-1-phosphate/ phosphatidylinositol-3-kinase/Akt pathway. Stroke. 2010; 41:1521-7. doi: 10.1161/STROKEAHA.110.583757.

37. Pan R, Rong Z, She Y, Cao Y, Chang LW, Lee WH. Sodium pyruvate reduces hypoxic-ischemic injury to neonatal rat brain. Pediatr Res. 2012; 72:479-89. doi: 10.1038/ pr.2012.107.

38. Bernier M, Wahl D, Ali A, Allard J, Faulkner S, Wnorowski A, Sanghvi M, Moaddel R, Alfaras I, Mattison JA, Tarantini S, Tucsek Z, Ungvari Z, et al. Resveratrol supplementation confers neuroprotection in cortical brain tissue of nonhuman primates fed a high-fat/ sucrose diet. Aging (Albany NY). 2016; 8:899-916. doi: 10.18632/aging.100942.

39. Renaud J, Martinoli MG. Resveratrol as a Protective Molecule for Neuroinflammation: A Review of Mechanisms. Current Pharmaceutical Biotechnology. 2014; 15:318-29. doi.

40. Bonestroo HJ, Nijboer $\mathrm{CH}$, van Velthoven CT, Kavelaars A, Hack CE, van Bel F, Heijnen CJ. Cerebral and hepatic inflammatory response after neonatal hypoxia-ischemia in newborn rats. Dev Neurosci. 2013; 35:197-211. doi: 10.1159/000346685.

41. Hagberg H, Mallard C, Ferriero DM, Vannucci SJ, Levison SW, Vexler ZS, Gressens P. The role of inflammation in perinatal brain injury. Nat Rev Neurol. 2015; 11:192-208. doi: 10.1038/nrneurol.2015.13.
42. Hedtjarn M, Leverin AL, Eriksson $\mathrm{K}$, Blomgren $\mathrm{K}$, Mallard C, Hagberg H. Interleukin-18 involvement in hypoxic-ischemic brain injury. J Neurosci. 2002; 22:5910-9. doi: 20026587.

43. Li SJ, Liu W, Wang JL, Zhang Y, Zhao DJ, Wang TJ, Li YY. The role of TNF-alpha, IL-6, IL-10, and GDNF in neuronal apoptosis in neonatal rat with hypoxic-ischemic encephalopathy. Eur Rev Med Pharmacol Sci. 2014; 18:905-9. doi.

44. Teo JD, Morris MJ, Jones NM. Hypoxic postconditioning reduces microglial activation, astrocyte and caspase activity, and inflammatory markers after hypoxia-ischemia in the neonatal rat brain. Pediatr Res. 2015; 77:757-64. doi: 10.1038/pr.2015.47.

45. Wang Z, Zhao H, Peng S, Zuo Z. Intranasal pyrrolidine dithiocarbamate decreases brain inflammatory mediators and provides neuroprotection after brain hypoxiaischemia in neonatal rats. Exp Neurol. 2013; 249:74-82. doi: 10.1016/j.expneurol.2013.08.006.

46. Hagberg H, Mallard C, Rousset CI, Xiaoyang W. Apoptotic mechanisms in the immature brain: involvement of mitochondria. J Child Neurol. 2009; 24:1141-6. doi: 10.1177/0883073809338212.

47. Wang X, Carlsson Y, Basso E, Zhu C, Rousset CI, Rasola A, Johansson BR, Blomgren K, Mallard C, Bernardi P, Forte MA, Hagberg H. Developmental shift of cyclophilin D contribution to hypoxic-ischemic brain injury. J Neurosci. 2009; 29:2588-96. doi: 10.1523/ JNEUROSCI.5832-08.2009.

48. Hu X, Li P, Guo Y, Wang H, Leak RK, Chen S, Gao Y, Chen J. Microglia/macrophage polarization dynamics reveal novel mechanism of injury expansion after focal cerebral ischemia. Stroke. 2012; 43:3063-70. doi: 10.1161/ STROKEAHA.112.659656.

49. De Simone R, Ajmone-Cat MA, Pandolfi M, Bernardo A, De Nuccio C, Minghetti L, Visentin S. The mitochondrial uncoupling protein-2 is a master regulator of both M1 and M2 microglial responses. J Neurochem. 2015; 135:147-56. doi: $10.1111 /$ jnc. 13244 .

50. Gaikwad SM, Heneka MT. Studying M1 and M2 states in adult microglia. Methods Mol Biol. 2013; 1041:185-97. doi: 10.1007/978-1-62703-520-0_18.

51. Blomgren K, Hagberg H. Free radicals, mitochondria, and hypoxia-ischemia in the developing brain. Free Radical Biology and Medicine. 2006; 40:388-97. doi: 10.1016/j. freeradbiomed.2005.08.040.

52. Thornton $\mathrm{C}$, Hagberg H. Role of mitochondria in apoptotic and necroptotic cell death in the developing brain. Clinica Chimica Acta. 2015; 451:35-8. doi: 10.1016/j. cca.2015.01.026.

53. Fang L, Gao H, Zhang W, Zhang W, Wang Y. Resveratrol alleviates nerve injury after cerebral ischemia and reperfusion in mice by inhibiting inflammation and apoptosis. Int J Clin Exp Med. 2015; 8:3219-26. doi. 
54. Wang X, Han W, Du X, Zhu C, Carlsson Y, Mallard C, Jacotot E, Hagberg H. Neuroprotective effect of Baxinhibiting peptide on neonatal brain injury. Stroke. 2010; 41:2050-5. doi: 10.1161/STROKEAHA.110.589051.

55. Levine S. Anoxic-ischemic encephalopathy in rats. Am J Pathol. 1960; 36: 1-17. doi.

56. West T, Atzeva M, Holtzman DM. Pomegranate polyphenols and resveratrol protect the neonatal brain against hypoxicischemic injury. Dev Neurosci. 2007; 29:363-72. doi: $10.1159 / 000105477$.
57. Sonmez U, Sonmez A, Erbil G, Tekmen I, Baykara B. Neuroprotective effects of resveratrol against traumatic brain injury in immature rats. Neurosci Lett. 2007; 420: 133-7. doi: 10.1016/j.neulet.2007.04.070.

58. Wilhelm J, Pingoud A. Real-time polymerase chain reaction. Chembiochem. 2003; 4:1120-8. doi: 10.1002/ cbic. 200300662.

59. Pfaffl MW. A new mathematical model for relative quantification in real-time RT-PCR. Nucleic Acids Res. 2001; 29:e45. doi. 